\title{
Bovine cysticercosis and its food safety implications in Harari People's National Regional State, eastern Ethiopia
}

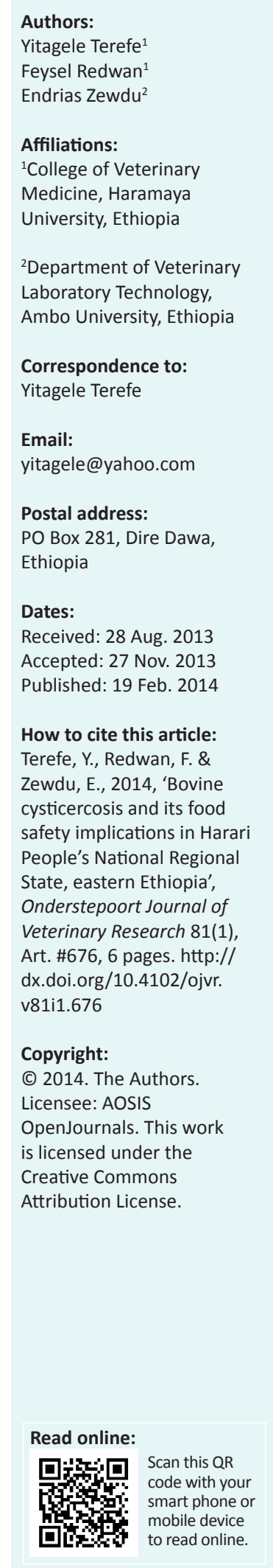

Taenia saginata cysticercosis is one of the zoonotic diseases that threaten food safety and food security, particularly in developing countries. A cross-sectional study was conducted to estimate the prevalence and cyst distribution in infected cattle, and food safety implications of Taenia saginata cysticercosis in Harari People's National Regional State, eastern Ethiopia. Post-mortem inspection of carcasses and organs of slaughtered cattle in Harar Municipal Abattoir, cyst viability tests and interviews with randomly selected meat consumers were undertaken. The post-mortem inspection showed that of the 898 local zebu cattle slaughtered for human consumption and examined for the presence of cysticerci of $T$. saginata, 19.7\% $(177 / 898 ; 95 \% \mathrm{CI}=17.2-22.5)$ harboured at least one cyst in the muscles or organs inspected. Of the edible anatomical sites with cysticerci, shoulder muscle, liver and heart together represented $65.4 \%, 66.0 \%$ and $65.4 \%$ respectively of relative prevalence, total cyst count and cyst viability. These edible sites are preferred above others by local people for preparation and consumption of raw or inadequately cooked meat dishes that are locally served as kurt, kitffo and dullet. The interviews revealed that among the 300 study participants, 182 (60.7\%) had been infected by taeniosis at least once during the previous year and of these $99.0 \%$ had eaten raw or undercooked beef, the majority $(88.3 \%)$ obtained from butchers assumed to provide officially inspected meat that was fit for consumption. This indicated that existing meat inspection processes were inadequate to prevent carcasses infected with $T$. saginata cysticerci from reaching consumers. The high prevalence of viable cysts in the edible parts of beef together with the widespread consumption of raw or undercooked beef indicated the importance of $T$. saginata cysticercosis as a food safety problem in eastern Ethiopia. The promotion of policies to upgrade existing meat inspection procedures and public education to ensure effective prevention of $T$. saginata taeniosis in humans were recommended.

\section{Introduction}

Foods of animal origin are often the preferred source of protein. However, if not properly prepared or handled, they can lead to food-borne infections. Cysticercosis caused by Taenia saginata is among the diseases that affect food safety (Gajadhar, Scandrett \& Forbes 2006). Taenia saginata cysticercosis or bovine cysticercosis, caused by the metacestodes of T. saginata, is a cosmopolitan disease occurring in industrialised as well as developing countries (Dorny et al. 2009). The European Parliament and Council in its Directive 2003/99EC identified T. saginata cysticercus as one of the major food-borne pathogens that should be monitored to protect human health (Abuseir et al. 2006). The prevalence is considered to be higher in developing countries because of poor sanitation, traditional cattle husbandry systems and inadequate meat inspection facilities (Cabaret et al. 2002; Dorny \& Praet 2007). As a result, the quality of human life, the aesthetic value of meat and the trading of meat and offal are compromised (Alum, Rubino \& Ijaz 2010; Dorny \& Praet 2007; Gajadhar et al. 2006).

Taeniosis or bovine cysticercosis has been recognised as a common problem in Ethiopia for many years (Webb 1957). Previous studies have indicated that taeniosis or bovine cysticercosis is an important meat-borne zoonosis that affects the safety of food presented for human consumption in different areas of the country. The reported prevalence of T. saginata taeniosis in the human population in Ethiopia has been found to range from 31.0\% to 89.4\% (Abunna et al. 2008; Bedu et al. 2011; Endris \& Negussie 2011; Megersa et al. 2010; Tembo 2001). The reported prevalence of bovine cysticercosis in cattle populations across various regions of Ethiopia was reported to range between $2.2 \%$ to $26.3 \%$ (Kumar \& Tadesse 2011).

Beef production in eastern Ethiopia is growing steadily to meet the ever-increasing demand for 'Harar senga', in other words, beef cattle that provide high quality meat that is consumed raw or in the kurt tradition. In Ethiopia there is a deep-rooted culture of consuming raw or inadequately 
cooked beef (Kumar \& Tadesse 2011; Tembo 2001). Formulating a strategy for controlling the associated disease prevalence is a first step in the management of disease, but the epidemiological data for T. saginata cysticercosis in Ethiopia are inadequate to develop effective recommendations.

The objectives of this study were to estimate the prevalence and distribution of cysts in infected cattle and to assess the food safety implications of T. saginata cysticercosis in cattle in Harari People's National Regional State, eastern Ethiopia.

\section{Materials and methods Description of the study area}

The study was conducted in Harar town in Harari People's National Regional State, located at $9^{\circ} 18^{\prime} 43^{\prime \prime} \mathrm{N}$ latitude and $42^{\circ} 7^{\prime} 23^{\prime \prime} \mathrm{E}$ longitude, $515 \mathrm{~km}$ east of Addis Ababa. The elevation of the town varies from $1600 \mathrm{~m}$ to $1920 \mathrm{~m}$ above sea level. The Regional State has 52245 cattle, 5631 sheep, 45256 goats and 53277 poultry (Central Statistical Agency 2011); the human population consists of 99321 urban and 84023 rural residents. The health facilities in Harar town comprise four hospitals, 32 clinics, nine pharmacies and 16 drug shops owned by the Ministry of Health and private entrepreneurs (Central Statistical Agency 2008).

\section{Harar Municipal Abattoir}

The abattoir is owned by the Harari People's National Regional Administrative Office, which aims to provide officially inspected and safe meat (beef, goat meat, mutton and camel meat) for consumers. The abattoir has separate compartments to slaughter animals for Christian and Muslim residents. On average 90 cattle for Christians and 70 cattle for Muslims are slaughtered per week. The routine meat inspection service is provided by two animal health assistant veterinarians employed by the Animal Health Department of the Regional Agricultural Office.

\section{Origin and management of study animals}

Cattle used for this study were local zebu (Bos indicus), which originated from the surrounding areas of the East Hararghe Zone of Oromia Regional State, specifically the areas Fedis, Kombolcha, Haramaya, Kulbi, Chelenko, Babile and Gursum. As in many other parts of Ethiopia, these areas use an extensive cattle management system where animals graze freely on available natural pasture, including bushes where some members of the community defecate in the open. Animals also often drink water from wells or streams that may be contaminated by effluent from open sewers.

\section{Study design}

A cross-sectional study was carried out from October 2009 to September 2010 on cattle slaughtered at Harar Municipal Abattoir. By following a systematic random sampling method, a total of 898 cattle were randomly sampled and routinely inspected for the presence of $T$. saginata metacestodes in edible parts of the slaughtered cattle. The required sample size of the study was determined as described by Thrusfield (2007) with a $95 \%$ confidence interval and 5\% desired precision. In the absence of published evidence of disease presence in the study area, a value of $50 \%$ was assumed; this corresponded to a required minimum sample size of 384 .

\section{Study methodology Abattoir survey}

Ante-mortem and post-mortem examinations were conducted by visiting the abattoir three days a week. For the ante-mortem examination cattle were randomly selected by lottery. They were tagged with an identification number and sex, age and origin were recorded. Age estimation was done based on owner information and dentition. For the post-mortem examination the heart, liver, lung, tongue, masseter muscle, shoulder muscle, neck muscle, intercostal muscle and diaphragm were inspected for the presence of cysticerci by applying a two-stage meat inspection procedure stipulated by Ethiopian Ministry of Agriculture Meat Inspection Regulations (Ministry of Agriculture 1972). During the first stage, visualisation and palpation of organs, muscles and carcass were carried out; during the second stage, further incisions were done in each case where one or more cysticerci were found (Gracey, Collins \& Huey 1999).

\section{Cyst distribution and characterisation}

Anatomical distribution of the cysts by organ or muscle affected and their status as active (fluid-filled) or calcified were determined, as described by Gracey et al. (1999). All suspected active cysts found during post-mortem examination were removed with the surrounding tissue, enclosed in labelled bottles and taken to the Veterinary Parasitology Laboratory at Haramaya University. The viability of the cysts was tested in the laboratory by incubating them at $37^{\circ} \mathrm{C}$ in $30 \%$ ox bile dissolved in normal saline for about one to two hours. A cyst was regarded as viable if the scolex evaginated during incubation. Taenia saginata metacestodes were identified by the cysticercus size, presence of a rostellum and absence of hooks on the rostellum of the evaginated cyst (Gracey et al. 1999).

\section{Questionnaire survey}

A questionnaire survey was conducted to assess the food safety significance of $T$. saginata cysticercosis. It relied on the participant's self-reported experiences to diagnose T. saginata taeniosis. The structured questionnaire comprised questions to obtain background information about the participants as well as 11 multiple choice questions, which had been pretested on 50 randomly selected individuals not included in the survey. The questionnaire was designed to obtain information on each participant's opinion on the status of $T$. saginata taeniosis; this included their awareness of taeniosis as a meat-borne zoonosis, presence of proglottids in their faeces, in their underwear or on their body during the previous 12 months (between 2008/2009 and 2009/2010), the source and type of meat consumed, whether it was consumed raw or undercooked and if so in which form, namely kurt or 
raw beef; kitffo, traditional Ethiopian food made from raw, finely chopped red lean beef mixed with butter and spices (pepper, sitchini); or dullet, an Ethiopian traditional food prepared from raw or undercooked finely chopped offal (kidney, liver, heart, rumen) mixed with spices and butter or oil. Three hundred randomly selected volunteer participants from the urban population in Harar town from whom consent was obtained were interviewed in one of their own local languages, namely Amharic, Oromiffa or Harari. Following detailed discussion about the objectives of the study with each participant, the interview was conducted face-to-face.

\section{Data handling, management and analysis}

Abattoir and questionnaire data were entered into Microsoft Excel, coded and analysed using the statistical package SPSS version 15.0. Descriptive statistics were used to summarise the data collected. The prevalence rate of bovine cysticercosis and T. saginata taeniosis was calculated as the number of cattle found positive for at least one cyst (active or calcified) during meat inspection divided by 898 and the number of participants replying that they had noticed proglottids divided by 300, respectively. Non-collinear variables with $p$-value $\leq 0.05$ in the univariate logistic regression were used to fit the multivariable logistic regression model. Odds ratio was used to assess the associations between different risk factors and prevalence. A confidence level of $95 \%$ was used. A $p$-value $\leq 0.05$ was considered statistically significant.

\section{Results}

\section{Prevalence of bovine cysticercosis and associated risk factors}

As shown in Table 1, the abattoir survey showed that $19.7 \%$ (95\% CI $=17.2-22.5)$ of the cattle examined were positive

TABLE 1: Prevalence of Taenia saginata cysts in cattle slaughtered in Harar Municipal Abattoir.

\begin{tabular}{lll}
\hline Organ or muscle affected & Number of cattle affected & \% affected \\
\hline Shoulder & 35 & 19.8 \\
Liver & 35 & 19.8 \\
Tongue & 25 & 14.1 \\
Masseter & 19 & 10.7 \\
Heart & 17 & 9.6 \\
Shoulder and masseter & 13 & 7.3 \\
Shoulder and tongue & 13 & 7.3 \\
Liver, masseter and tongue & 7 & 3.9 \\
Liver, shoulder and heart & 13 & 7.3 \\
\hline Total & $\mathbf{1 7 7}$ & $\mathbf{1 9 . 7}$ \\
\hline
\end{tabular}

$n=898$. for the presence of at least one cyst in the organs or muscles inspected. The prevalence of bovine cysticercosis did not show any significant difference between male and female, different age groups or origin of cattle (see Table 2).

\section{Anatomical distribution and characterisation of cysts}

The liver, shoulder, tongue, heart and masseter harboured at least one cyst. Shoulder muscles were the most frequently infected $(30.5 \%)$, followed by the liver $(22.6 \%)$ and tongue (18.5\%) (see Table 3). Among the 177 cattle harbouring metacestodes of $T$. saginata (see Table 1), 131 (74.0\%) had at least one cyst in a single organ or muscle whereas the remaining $46(26.0 \%)$ had cysticerci in more than one organ or muscle.

The number of cysts found in a given organ or muscle ranged from one to nine; the highest number was recorded in the shoulder muscle. Among the different parts affected, shoulder muscles, liver and heart together accounted for $65.4 \%, 66.0 \%$ and $65.4 \%$ relative prevalence, cyst count and relative viability respectively (see Table 3 and Table 4 ).

Out of 661 cysts examined, 185 (28.0\%), 284 (43.0\%) and 192 $(29.0 \%)$ were found to be viable, non-viable and calcified, respectively. The highest relative viability was recorded in the masseter muscle (31.3\%), then the liver (30.1\%) and shoulder muscles (27.2\%) (see Table 4).

\section{Status of Taenia saginata taeniosis as a meat- borne zoonosis in Harar town}

Among the 300 people involved in the questionnaire survey, $182(60.7 \%)$ reported $T$. saginata infection. The positive respondents confirmed that they had experienced $T$. saginata taeniosis by observing the white segments or proglottids expelled either in their faeces, underwear or on the body at least once in the previous year (between 2008/2009 and $2009 / 2010$ ). It was found that $65 \%$ of respondents, who had sufficient knowledge of the risk of consumption of raw or undercooked meat and on taeniosis as a meat-borne zoonosis, reported $T$. saginata taeniosis. It was shown that $88 \%$ of the people involved in this study purchased beef from butcher shops that provide officially inspected beef for consumption. However, $62 \%$ of them acquired T. saginata taeniosis (see Table 5). The prevalence of $T$. saginata taeniosis had a statistically significant association $(p<0.05)$ with the

TABLE 2: Occurrence of Taenia saginata cysts with regard to sex, age and origin of cattle slaughtered.

\begin{tabular}{|c|c|c|c|c|c|c|c|}
\hline Risk factor & Category & Number examined & Number positive & $\%$ prevalence & Odds ratio & $95 \% \mathrm{Cl}$ & $p$-value \\
\hline \multirow[t]{2}{*}{ Sex } & Female & 168 & 31 & 18.5 & 1.00 & - & - \\
\hline & Male & 730 & 146 & 20.0 & 1.10 & $0.72,1.70$ & 0.649 \\
\hline \multirow[t]{2}{*}{ Age } & $\leq 5$ years & 234 & 38 & 16.2 & 1.00 & - & - \\
\hline & $>5$ years & 664 & 139 & 20.9 & 1.37 & $0.92,2.03$ & 0.122 \\
\hline \multirow[t]{5}{*}{ Origin } & Fedis & 165 & 27 & 16.4 & 1.00 & - & - \\
\hline & Gursum & 163 & 30 & 18.4 & 1.15 & $0.65,2.04$ & 0.626 \\
\hline & Kombolcha & 141 & 28 & 19.9 & 1.27 & $0.71,2.27$ & 0.428 \\
\hline & Babile & 239 & 50 & 20.9 & 1.35 & $0.81,2.27$ & 0.253 \\
\hline & Others $\dagger$ & 190 & 42 & 22.1 & 1.45 & $0.85,2.48$ & 0.174 \\
\hline
\end{tabular}

$\dagger$, Chelenko, Kulbi or Weter. 
TABLE 3: Distribution of cysticerci of Taenia saginata in edible parts of infected cattle.

\begin{tabular}{|c|c|c|c|c|c|c|}
\hline \multirow[t]{2}{*}{ Edible parts } & \multirow[t]{2}{*}{ Number affected } & \multirow[t]{2}{*}{ Relative prevalence (\%) } & \multicolumn{4}{|c|}{ Cyst count } \\
\hline & & & Mean per organ & Range & Total & $\%$ \\
\hline Shoulder & 74 & 30.5 & 3.2 & $1-9$ & 239 & 36.2 \\
\hline Liver & 55 & 22.6 & 2.4 & $1-7$ & 133 & 20.1 \\
\hline Tongue & 45 & 18.5 & 2.5 & $1-6$ & 113 & 17.1 \\
\hline Masseter & 39 & 16.1 & 2.9 & $1-7$ & 112 & 16.9 \\
\hline Heart & 30 & 12.4 & 2.1 & $1-5$ & 64 & 9.7 \\
\hline Total & 243 & 100 & 2.7 & $1-9$ & 661 & 100 \\
\hline
\end{tabular}

TABLE 4: Characterisation of cysticerci of Taenia saginata collected from edible parts of infected cattle.

\begin{tabular}{|c|c|c|c|c|c|c|c|c|}
\hline \multirow[t]{2}{*}{ Edible parts } & \multirow[t]{2}{*}{ Viable } & \multirow[t]{2}{*}{$\%$} & \multirow[t]{2}{*}{ Non-viable } & \multicolumn{5}{|c|}{ Cyst characteristics } \\
\hline & & & & $\%$ & Calcified & $\%$ & Total & $\%$ \\
\hline Shoulder & 65 & 27.2 & 106 & 44.4 & 68 & 28.5 & 239 & 36.2 \\
\hline Liver & 40 & 30.1 & 63 & 47.4 & 30 & 22.6 & 133 & 20.1 \\
\hline Tongue & 29 & 25.7 & 47 & 41.6 & 37 & 32.7 & 113 & 17.1 \\
\hline Masseter & 35 & 31.3 & 37 & 33.0 & 40 & 35.7 & 112 & 16.9 \\
\hline Heart & 16 & 25.0 & 31 & 48.4 & 17 & 26.6 & 64 & 9.7 \\
\hline Total & 185 & 28.0 & 284 & 43.0 & 192 & 29.1 & 661 & 100 \\
\hline
\end{tabular}

TABLE 5: Participant perception, knowledge, source and habit of beef consumption on Taenia saginata taeniosis.

\begin{tabular}{|c|c|c|c|c|}
\hline Respondent view & Category & Number of respondents & Number of taeniosis positive & Number of taeniosis positive in $\%$ \\
\hline \multirow[t]{2}{*}{ Preferred meat } & Goat meat & 136 & 23 & 16.9 \\
\hline & Beef & 164 & 159 & 97.0 \\
\hline \multirow[t]{2}{*}{ Source of beef } & Other $\dagger$ & 35 & 18 & 51.4 \\
\hline & Butcher shop & 265 & 164 & 61.9 \\
\hline \multirow[t]{2}{*}{ Awareness of side-effects of raw meat consumption } & No & 26 & 5 & 19.2 \\
\hline & Yes & 274 & 177 & 64.6 \\
\hline \multirow[t]{2}{*}{ Habit of raw beef consumption } & No & 113 & 1 & 0.9 \\
\hline & Yes & 187 & 181 & 96.8 \\
\hline \multirow[t]{3}{*}{ Form of eating raw beef } & Dullet & 23 & 22 & 95.6 \\
\hline & Kitffo & 32 & 31 & 96.9 \\
\hline & Kurt & 132 & 128 & 97.0 \\
\hline \multirow{2}{*}{$\begin{array}{l}\text { Awareness of taeniosis as a possible meat-borne } \\
\text { zoonosis }\end{array}$} & No & 26 & 5 & 19.2 \\
\hline & Yes & 274 & 177 & 64.6 \\
\hline
\end{tabular}

$\dagger$, Backyard butcher, street vendor.

habit of eating raw or undercooked beef, sex, age, religion, marital status and income of the respondents (see Table 6).

\section{Discussion}

Meat inspection revealed that the prevalence of $T$. saginata cysticercosis in the Harari People's National Regional State was about $20.0 \%$. This is higher than previously recorded for Kombolcha in north-eastern Ethiopia (6.7\%) (Endris \& Negussie 2011), Jimma in south-western Ethiopia (2.9\% and 4.4\%) (Megersa et al. 2010; Tolosa et al. 2009), Wolita Sodo (11.3\%) (Regassa et al. 2009) and Ziway (3.0\%) (Bedu et al. 2011) in southern Ethiopia. The present result was lower than found in Hawassa in southern Ethiopia (26.3\%) (Abunna et al. 2008) and similar to that found in north-western Ethiopia (18.5\%) (Kebede 2008). However, large differences can also be found within a region. In two studies conducted in and around Addis Ababa in central Ethiopia, prevalence varied between $7.5 \%$ (Kebede, Tilahun \& Hailu 2009) and $89.4 \%$ (Tembo 2001). Such differences in prevalence may be associated with the number of cattle examined, the sensitivity of the meat inspection procedures, which can be affected by the site and method of incision, abattoir facilities and management, the motivation and competency of the meat inspectors and the willingness of the owner to cooperate (Abunna et al. 2008; Dorny \& Praet 2007; Wanzala et al. 2003).
The geographical differences in the habit of raw meat consumption, environmental and personal hygiene, animal husbandry practices, proximity to waste water and accessibility of taenicides for treating animals might also contribute to differences in prevalence (Cabaret et al. 2002; Dorny \& Praet 2007; Kumar \& Tadesse 2011; Wanzala et al. 2003). To obtain the best estimate of the prevalence of $T$. saginata cysticercosis and increased confidence in the results of this study, the researchers negotiated with butchers so that multiple incisions could be made during inspection; they also performed a detailed examination of all muscles and organs.

The post-mortem examination identified that among the edible parts investigated the liver, shoulder, tongue, heart and masseter muscle require careful inspection to identify the cyst. Shoulder and masseter muscles (Abunna et al. 2008), shoulder, heart and tongue (Megersa et al. 2010), and heart, masseter, tongue, triceps and thigh muscles (Kebede 2008) previously have been reported as major sites to be inspected.

Shoulder muscles, liver and heart, which together constituted $65.4 \%, 66.0 \%$ and $65.4 \%$ relative prevalence, total cyst count and relative viability of the cysts respectively, are also the main components of the locally prepared traditional dishes of raw or undercooked meat called kurt, kitffo and 


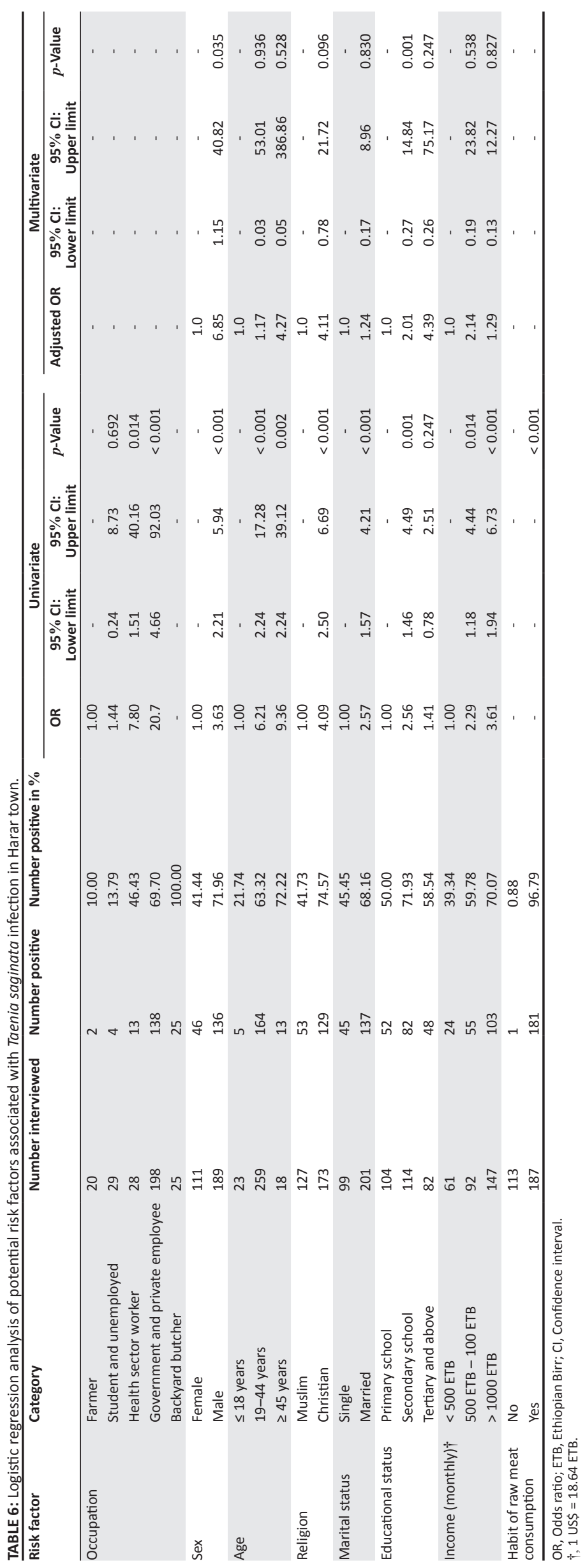

dullet. The participants in this study indicated their strong preference for these dishes, highlighting their potential for strong links to T. saginata cysticercosis (Abunna et al. 2008; Endris \& Negussie 2011; Kebede 2008; Megersa et al. 2010). To safeguard consumer health, it is therefore essential to increase the area and number of edible sites examined during meat inspection (Wanzala et al. 2003). As incising the meat at a large number of different sites to allow a more detailed examination reduces the market value of the carcass, these inspections will require the full support of butchers.

The high prevalence $(60.7 \%)$ of taeniosis recorded in Harar town was similar to that found in Hawassa (64.2\%) (Abunna et al. 2008), Ziway (56.7\%) (Bedu et al. 2011) and Jimma (56.7\%) (Megersa et al. 2010). It was higher than the report from Kombolcha (31\%) (Endris \& Negussie 2011). The difference in prevalence of $T$. saginata taeniosis in different areas may be associated with the difference in occurrence of cysticercosis in cattle, the level of raw meat consumption and the meat inspection procedures practised. Reports have indicated that the prevalence of $T$. saginata taeniosis may also vary in relation to age, sex, religion, marital status, educational status and income of individual (Abunna et al. 2008; Bedu et al. 2011; Endris \& Negussie 2011; Megersa et al. 2010).

Previous reports from Ethiopia indicated that consumption of raw or inadequately cooked beef was strongly associated with T. saginata infection (Abunna et al. 2008; Bedu et al. 2011; Endris \& Negussie 2011; Megersa et al. 2010). Of the 300 respondents interviewed, $54.7 \%$ preferred beef and $45.3 \%$ goat; $97.0 \%$ of the former and only $17.0 \%$ of the latter acquired T. saginata taeniosis. Even though no respondents preferred mutton or pork, they stated that they may eat mutton on festive or social occasions but never eat pork. Of the $62.0 \%$ who ate raw or inadequately cooked beef in any of the three forms, more than $97.0 \%$ acquired T. saginata taeniosis, confirming that kurt, kitffo and dullet are all sources of viable cysts of the parasite, as found in previous studies (Abunna et al. 2008; Bedu et al. 2011; Endris \& Negussie 2011; Megersa et al. 2010). It is therefore wise to focus strongly on those edible sites of the carcass used for the preparation of these traditional dishes during meat inspection and public education.

Among the 300 study participants, 265 (88.3\%) used meat from butcher shops presumed to provide officially inspected meat, and of the $182(60.7 \%)$ people who acquired T. saginata taeniosis, 164 (90.1\%) reportedly purchased their meat from these butcher shops. The high prevalence of $T$. saginata taeniosis recorded in the survey suggests that meat inspections fail to detect the presence of the cysts and as a result infected meat is commonly passed for human consumption (Wanzala et al. 2003). Poor working conditions and high workload in the abattoir, as observed by the researchers, might have contributed to this apparent low efficiency of meat inspection. Dorny and Praet (2007) demonstrated an association between capacity to undertake proper and sensitive meat inspections and motivation of the meat inspectors; thus proper facilities form a crucial part of providing safe food for consumers. 
The researchers recognise the deep-rooted culture of consumption of raw or undercooked beef in Ethiopia. Over $90 \%$ of respondents were aware of the risk of consumption of raw or undercooked beef; however, $65 \%$ of them nevertheless reported being infected with $T$. saginata taeniosis. This finding is consistent with other reports that showed the overriding influence of culture on the consumption of raw or undercooked beef, irrespective of age, religion, marital status and income of the individuals (Abunna et al. 2008; Girma et al. 2012; Megersa et al. 2010).

\section{Conclusion}

There was a high prevalence of $T$. saginata cysts in edible anatomical sites of cattle from Harari People's National Regional State in eastern Ethiopia. A high prevalence of $T$. saginata taeniosis was strongly associated with the consumption of raw or inadequately cooked beef. Thus $T$. saginata cysticercosis is an economically important disease in cattle in this region, requiring effective interventions to ensure food safety. The study highlights the need to strengthen meat inspection services through multisectoral collaboration involving the human health, veterinary public health and educational sectors to better control the source and expression of the disease. It is recommended that continuous public education programmes are provided particularly to school children, who might serve as a foundation for bringing about cultural change in the long term that leads to avoidance of raw or inadequately cooked meat consumption.

\section{Acknowledgments}

The authors would like to thank the Haramaya University for the financial support to conduct this study. We also thank the Institute of Tropical Medicine (ITM), Antwerp, Belgium who funded the first author to attend the scientific research paper writing workshop that facilitated the writing of this paper. Our sincere appreciation also goes to Dr Chris Beadle of CSIRO, Australia for critically reviewing and editing this article. Finally, we are very grateful to the Harar Municipal Abattoir meat inspectors, owners of butcher shops and study participants for their collaboration, enthusiasm and willingness to share their experiences during this study.

\section{Competing interests}

The authors declare that they have no financial or personal relationship(s) which may have inappropriately influenced them in writing this article.

\section{Authors' contributions}

Y.T. (Haramaya University) designed the study, conducted the questionnaire survey, analysed the data and prepared the manuscript. F.R. (Haramaya University) conducted the abattoir survey and the writing of the manuscript, and E.Z. (Ambo University) participated in the design of the study, the analysis and interpretation of the data and the critical evaluation of the draft.

\section{References}

Abunna, F., Tilahun, G., Megersa, B., Regassa, A. \& Kumsa, B., 2008, 'Bovine cysticercosis in cattle slaughtered at Awassa municipal abattoir, Ethiopia: Prevalence, cyst viability, distribution and its public health implication', Zoonoses and Public Health 55, 82-88. http://dx.doi.org/10.1111/j.1863-2378.2007.01091.x

Abuseir, S., Epe, C., Schnieder, T., Klein, G. \& Kuhne, M., 2006, 'Visual diagnosis of Taenia saginata cysticercosis during meat inspection: Is it unequivocal?', Parasitology Research 99, 405-409. http://dx.doi.org/10.1007/s00436-0060158-3

Alum, A., Rubino, J.R. \& ljaz, M.K., 2010, 'The global war against intestinal parasites Should we use a holistic approach?', International Journal of Infectious Diseases 14, 732-738. http://dx.doi.org/10.1016/j.ijid.2009.11.036

Bedu, H., Tafess, K., Shelima, B., Woldeyohannes, D., Amare, B. \& Kassu, A., 2011 'Bovine cysticercosis in cattle slaughtered at Zeway municipal abattoir: Prevalence and its public health importance', Journal of Veterinary Science and Technology 2,1-5. http://dx.doi.org/10.4172/2157-7579.1000108

Cabaret, J., Geerts, S., Madeline, M., Ballandonne, C. \& Barbier, D., 2002, 'The use of urban sewage sludge on pastures: The cysticercosis threat', Veterinary Research 33, 575-597.

Central Statistical Agency, 2008, Summary and statistical report of the 2007 population and housing census, Federal Democratic Republic of Ethiopia Population Census Commission, Addis Ababa. http://dx.doi.org/10.1051/vetres:2002040

Central Statistical Agency, 2011, Report on livestock and livestock characteristics: Agricultural Sample Survey Volume II, Federal Democratic Republic of Ethiopia Central Statistical Agency, Addis Ababa.

Dorny, P. \& Praet, N., 2007, 'Taenia saginata in Europe', Veterinary Parasitology 149 22-24. http://dx.doi.org/10.1016/j.vetpar.2007.07.004

Dorny, P., Praet, N., Deckers, N. \& Gabriel, S., 2009, 'Emerging food-borne parasites', Veterinary Parasitology 163, 196-206. http://dx.doi.org/10.1016/j. vetpar.2009.05.026

Endris, J. \& Negussie, H., 2011, 'Bovine cysticercosis: Prevalence, cyst viability and distribution in cattle slaughtered at Kombolcha Elfora Meat Factory, Ethiopia', American-Eurasian Journal of Agriculture and Environmental Science 11, 173-176.

Gajadhar, A.A., Scandrett, W.B. \& Forbes, L.B., 2006, 'Overview of food- and waterborne zoonotic parasites at the farm level', Revue scientifique et technique de I'Office international des Épizooties 25, 595-606.

Girma, S., Mammo, A., Bogale, K., Sori, T., Tadesse, F. \& Jibat, T., 2012, 'Assessment of awareness on food-borne zoonoses and its relation with veterinary public health services in and around Addis Ababa', Journal of Public Health and Epidemiology 4, 48-51.

Gracey, J.F., Collins, D.S. \& Huey, R.J., 1999, Meat hygiene, W.B. Saunders, Philadelphia.

Kebede, N., 2008, 'Cysticercosis of slaughtered cattle in northwestern Ethiopia', Research in Veterinary Science 85, 522-526. http://dx.doi.org/10.1016/j. rvsc.2008.01.009

Kebede, N., Tilahun, G. \& Hailu, A., 2009, 'Current status of bovine cysticercosis of slaughtered cattle in Addis Ababa Abattoir, Ethiopia', Tropical Animal Health and Production 41, 291-294. http://dx.doi.org/10.1007/s11250-008-9188-4

Kumar, A. \& Tadesse, G., 2011, 'Bovine cysticercosis in Ethiopia: A review', Ethiopian Veterinary Journal 15, 15-35. http://dx.doi.org/10.4314/evj.v15i1.67681

Megersa, B., Tesfaye, E., Regassa, A., Abebe, R. \& Abunna, F., 2010, 'Bovine cysticercosis in cattle slaughtered at Jimma Municipal Abattoir, South Western cysticercosis in cattle slaughtered at Jimma Municipal Abattoir, South Western Ethiopia: Prevalence, cyst viability and its socio-economic importance',
World 3, 257-262. http://dx.doi.org/10.5455/vetworld.2010.257-262

Ministry of Agriculture, 1972, Meat Inspection Regulations, Legal notice No. 428, Negarite Gazeta, Ministry of Agriculture, Addis Ababa.

Regassa, A., Abunna, F., Mulugeta, A. \& Megersa, B., 2009, 'Major metacestodes in cattle slaughtered at Wolaita Soddo Municipal abattoir, Southern Ethiopia: Prevalence, cyst viability, organ distribution and socioeconomic implications', Tropical Animal Health and Production 41, 1495-1502. http://dx.doi.org/10.1007/ s11250-009-9338-3

Tembo, A., 2001, 'Epidemiology of Taenia saginata taeniasis and cysticercosis in three selected agro climatic zones in central Ethiopia', MSc thesis, Faculty of Veterinary Medicine, Addis Ababa University and Free University of Berlin.

Thrusfield, M., 2007, Veterinary Epidemiology, Blackwell Science, Oxford.

Tolosa, T., Tigre, W., Teka, G. \& Dorny, P., 2009, 'Prevalence of bovine cysticercosis and hydatidosis in Jimma municipal abattoir, South West Ethiopia', Onderstepoort Journal of Veterinary Research 76, 323-326. http://dx.doi.org/10.4102/ojvr. v76i3.37

Wanzala, W., Onyango-Abuje, J.A., Kang'ethe, E.K., Zessin, K.H., Kyule, N.M., Baumann M.P. et al. 2003, 'Control of Taenia saginata by post-mortem examination of M.P. et al. 2003, 'Control of Taenia sagin
carcasses', African Health Science 3, 68-76.

Webb, A.H., 1957, 'Intestinal parasitism in Beghemdir Province, Ethiopia', Journal of the National Medical Association 49, 310-314. 